\title{
Slope stability in landform design
}

\author{
R Knutsson Luleå University of Technology, Sweden
}

A Bjelkevik Tailings Consultants Scandinavia AB, Sweden

S Knutsson Luleå University of Technology, Sweden

\begin{abstract}
Tailings storage facilities (TSFs) will, after closure of the mine, have to be stable in a long-term perspective (e.g. 1,000 years or more). In many cases, due to the characteristics of the tailings, a high phreatic surface is required to keep the tailings saturated in order to prevent, or minimise, the process of oxidation. Due to this the slope stability of the embankment, or the land form slope, is critical as any material exposed to a hydraulic gradient is exposed to a load. So, the question is:

Is the embankment, or landfill slope, that is exposed to a hydraulic gradient safe in the long term with respect to the actual design and material properties?

In order to answer that question, an understanding of the structure, its stability and level of actual safety during operation is necessary. This paper will therefore discuss slope stability for embankments during operation and the long-term perspective and how the factor of safety (FS) can be verified. Practice today for dam stability is that a certain FS is required, i.e. a safety margin (in Sweden FS>1.5), and for that condition we design the embankment. The design includes the geometry of the structure, material properties, water management/water levels and requirements for compatibility between different materials, as well as for construction and operation. The FS can, however, not be physically measured on, or in, the actual embankment. What can be measured is seepage, pore pressure and movement (vertical and horizontal displacements). But how can the readings be used to verify the actual FS? In order to illustrate this, an example from a TSF in northern Sweden is presented where readings have been taken through numerical modelling (PLAXIS), comprehensive geotechnical investigations, lab testing and inclinometers.
\end{abstract}

In order to predict how an embankment, or landform slope, will behave in the long-term phase and what the actual FS will be, the authors believe it is necessary to understand the behaviour of the structure during operation. The method used for the example illustrated in this paper shows a method to gain an understanding for a structure, which is absolutely crucial for understanding the actual FS and for the possibility to predict the level of safety in the long term.

\section{Introduction}

Tailings storage facilities (TSFs) are used extensively in the mining industry and have been in use for more than 100 years. The facilities are normally located to benefit from the landscape, e.g. in valleys, close to heights, etc. Very often, substantial parts of the TSFs are embankments used to enclose the tailings in order to manage it in a safe, environmentally acceptable and economical manner.

The design of these embankments differs from water retaining embankments, as tailings and water are stored together. In addition, they are normally constructed in stages in relation to mining operations. The construction time may thus be very long, sometimes several decades, leading to non-static conditions.

During the last decade, the importance of closure of TSFs has been highlighted and, correspondingly, the interest in how this should be done in a safe and reliable way. This is not only in the interest of the mining industry. Society, authorities and research organisations also show an increased interest in TSF closure measures. Closure is in this context the phase after the mine has closed down, or after the TSF has reached its full capacity. It is often generalised to be for periods in the range of 1,000 years or more. 
Dam safety is a crucial aspect, especially after closure, if a high phreatic surface is required in the TSF for 'perpetuity'. This might be the case if the characteristics of the deposited tailings should be kept saturated with water in order to prevent, or minimise, oxidation and acidification.

Traditionally, dam stability is requested as a Factor of Safety (FS) obtained by limit equilibrium methods. In Sweden, the requirement is FS>1.5 for normal conditions. This is based on geometry, material properties obtained from field investigations and/or laboratory tests, water levels and phreatic surface, etc.

In addition, embankment surveillance and monitoring of embankment behaviour are, for safety aspects, proposed in many guidelines (GruvRIDAS 2012; ICOLD 2011, 1996). Benefits of using instrumentation in the geotechnical field are described by Dunnicliff (1988).

When analyses are performed with the limit equilibrium method, it should be emphasised that a particular failure mode is analysed. The method cannot be used to understand how close, or far, the current state of the structure is from failure. It gives a theoretical value of the FS. The limit equilibrium method cannot visualise the behaviour of the structure, i.e. the embankment, or give values of deformation that can be compared with data measured in situ. Thus, it is not possible to understand, verify or visualise the current or the long-term mechanical behaviour of the structure.

To verify the performance of the embankment it is therefore important to use surveillance and monitoring measurements and compare measured results with calculated results. Abnormalities will then be recognised. Based on deformation records, warning criteria can be established in different ways, e.g. by deformation rates (Yin et al. 2010). Another approach is to use instrumentation data for soil parameter determination (back-analyses) c.f. (Marcato et al. 2012; Ostoprak \& Cinicioglu 2005; Vahdati et al. 2013). This can be used in observational methods (Ostoprak \& Cinicioglu 2005) or in cases where future deformations are to be estimated (Marcato et al. 2012).

In order to verify if an embankment or, in the long term a landfill slope, has the intended degree of safety with respect to the actual design and material properties, numerical modelling (e.g. finite element modelling) is suggested.

This paper discusses slope stability for embankments during operation and closure, long-term planning, and how the actual FS can be verified through field measurements.

A case is presented where numerical modelling (finite element method) has been used in order to estimate deformations and pore water pressures that can prevail in an embankment for a certain degree of safety. A method for determining early warning (alert) levels for measured parameters from instruments is proposed and described. The methodology is in accordance with Dunnicliff (1988) who used the three colours green, yellow and red to describe warning levels.

The method can be extended to cover the behaviour of an embankment for long-term sustainability, and actions to maintain the required FS can then be planned, e.g. for this case study the actions to be taken are placement of support fill on the downstream side of the embankment, which is also described.

\section{Case study}

For this study, an operating mine in northern Sweden was used. The mine has been in operation for nearly five decades and life-of-mine (LOM) is currently estimated for at least another three decades. Tailings generated from the extraction processes are hydraulically transported and deposited into the TSF using spigots at the crest of the embankment. The management of the TSF has changed with time as well as the design of the surrounding embankments. Originally, deposition of tailings was by single point discharge from one of the perimeter embankments. This led to settling of fine grained tailings in the pond close to the opposite downstream embankment. The downstream embankment was at this time raised as a downstream till embankment, with a rate of rise less than one metre per year. This methodology would then change, as tailings today are spigotted from this embankment and the construction method is changed to the upstream method using tailings (compare (a) and (b) in Figure 1). 


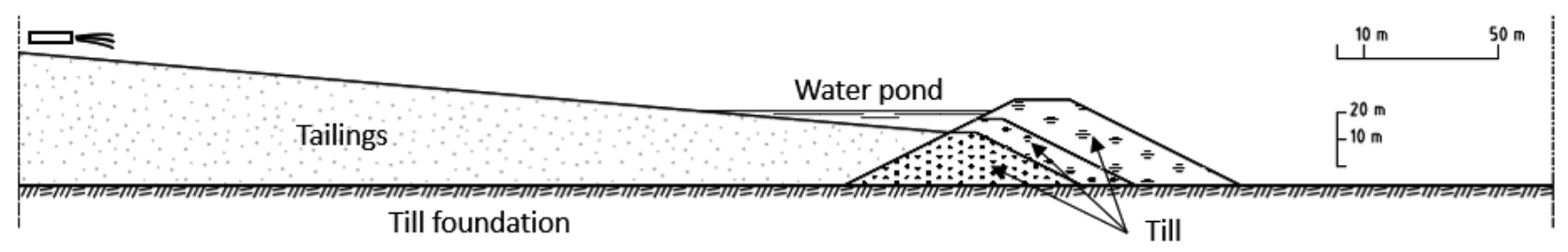

(a)

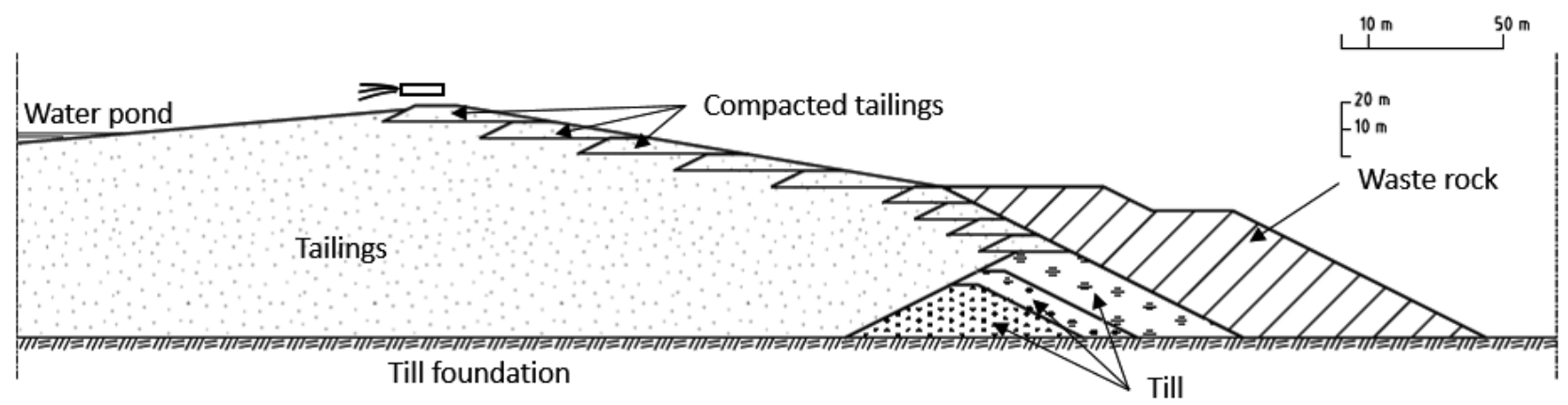

(b)

Figure 1 (a) The investigated embankment with original deposition of tailings towards the embankment and downstream raises using till; (b) the investigated embankment with the current situation, with tailings deposited from the embankment and upstream raises using tailings

The rate of rise is today about three metres per year due to increased production rate at the mine. On the downstream slope of the dam, waste rock is placed in order to maintain the sought stability. The waste rock wall is increased with time, based on stability analyses.

The TSF and its associated embankments have been studied regarding stability and performance by numerical modelling. Performance of the embankments is studied in terms of measurable properties such as pore water pressure and deformations.

By setting up a numerical model that corresponds to actual field conditions, the actual stability can be verified. This methodology is also valuable for the engineer to interpret field data. The methodology also forms a basis for long-term planning (after closure) of the TSF. Such modelling would help in estimations of future stability and embankment performance. Without a model that can estimate today's embankment performance, estimation for the long term would be unreliable.

In the following chapters, a description will be given regarding the methodology behind the modelling and its usage for estimation of future embankment performance.

\subsection{Numerical modelling}

In order to model the embankment's behaviour and corresponding stability, the embankment and its soil properties together with actual loading conditions should first be determined. By geotechnical surveys performed at the actual TSF and its associated embankments, soil properties and their mechanical behaviour were evaluated. In 2013, field investigations such as Cone Penetration Tests (CPTu) indicated that deposited tailings are stratified in nearly horizontal layers with altering properties (Jonasson 2013). Samples of tailings, both sampled as disturbed and undisturbed, were brought to the laboratory at Luleå University of Technology for testing.

Disturbed samples indicated tailings ranging from silty clay to silty sand, classified by fraction (Bhanbhro et al. 2013). Due to the changes in deposition methods, the fine grained tailings were found at the bottom of the impoundment in the area of the embankment studied, with increased grain sizes at higher elevations. 
Undisturbed samples were mainly used for mechanical tests such as drained triaxial tests and standard odometer tests (Bhanbhro 2013; Knutsson 2013). Based on the results from these tests, parameters were evaluated for the constitutive model 'Hardening Soil'. This model has the same failure criteria as the Mohr-Coulomb model (with strength parameters such as cohesion and friction angle), but is more accurate for simulation of soil deformations than the Mohr-Coulomb method due to additional stiffness parameters (Brinkgreve et al. 2014; Schanz 1999). It accounts for hardening effects and stress-dependent stiffness.

More effort is needed in the laboratory and corresponding evaluation when more advanced models are used, but in this case is considered to be required for better estimation of embankment deformations. In Figure 2 a triaxial tests series (from laboratory) is presented together with corresponding triaxial simulations. Even though full agreement is not reached, the hyperbolic relations and increased stiffness with increased radial stresses can be seen. These effects would not be able to be simulated with a linear elastic, perfectly plastic constitutive model such as Mohr-Coulomb.

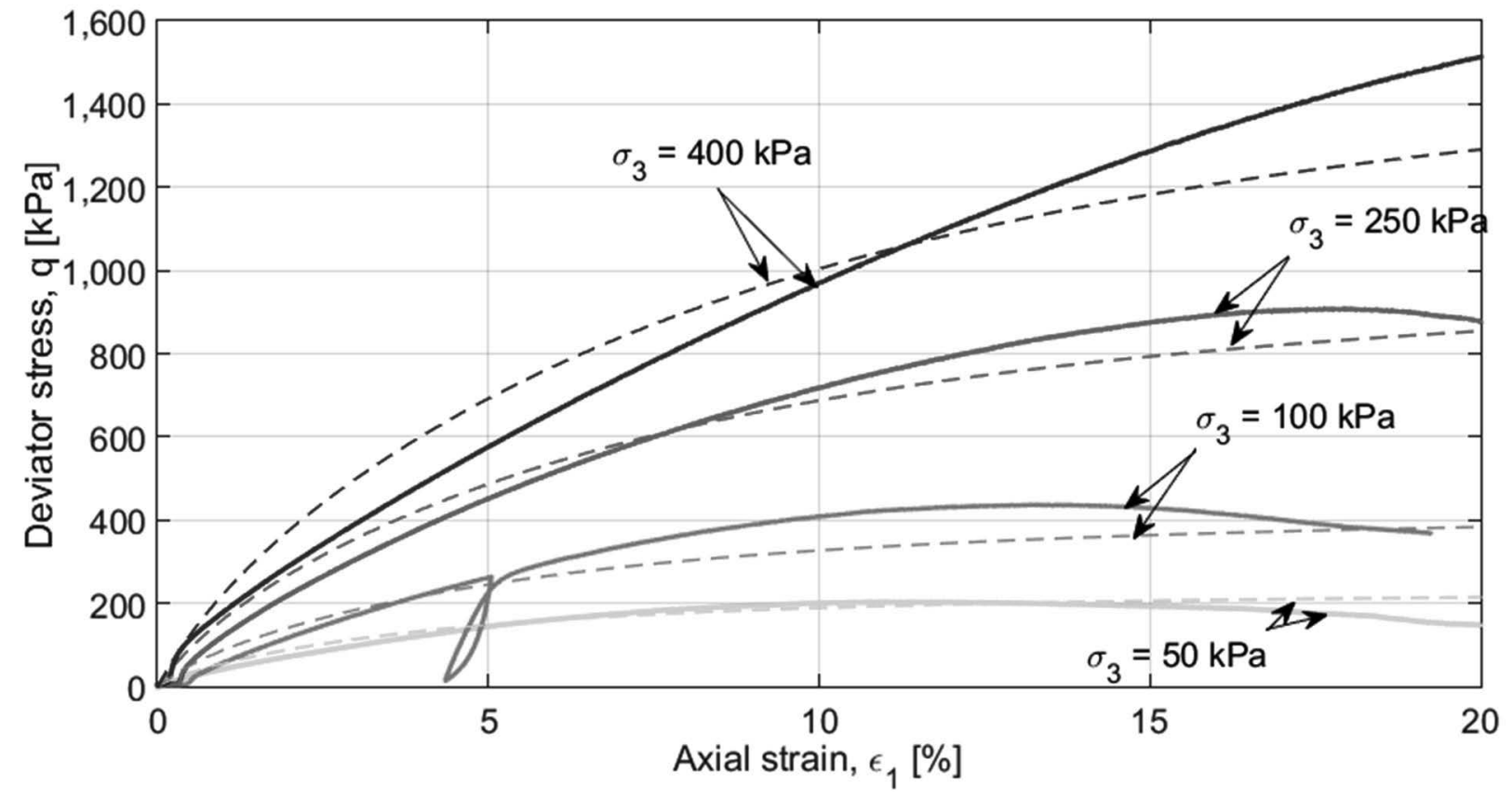

Figure 2 Example of a triaxial test series, laboratory data (continuous lines) versus simulation with Hardening Soil (dashed lines)

The geometry of the embankment's cross-section was imported to PLAXIS 2D where a model was built. PLAXIS is a finite element program, developed for the analysis of deformation, stability and groundwater flow in geotechnical engineering (Brinkgreve et al. 2014).

In order to fully simulate the embankment and present behaviour of the soil, historical events should be included in a model to cover all loading conditions (loading history) that have taken place at site. This would theoretically have covered all stress situations in the structure, which depend on factors such as rate of rise and water (pore water pressure) conditions. Due to lack of data of such events, this study was limited to cover events from 1992 and onwards, which is 24 years after the starter embankment was constructed. 1992 is the first year where airborne data surveys were performed from which data of TSF pond levels can be drawn. Such data, together with as-built drawings (history of embankment construction) and CPTuresults (tailings stratigraphy) were used to describe historical events in the model. The simulation of historical events was needed in order to compare numerical results with field observations. This will act as model confirmation.

For modelling of future behaviour, embankment raises, beach constructions (increased impoundment level) and 'resting phases' (where no deposition/spigotting of tailings takes place) were modelled according to a 'standard year'. Such a year includes all planned events that take place at the embankment over a year 
(P Marthin, personal communication, 5 September 2012), as illustrated in Figure 3. Here, an embankment raise is assumed to take 15 days starting 15 August. This phase is then followed by a 15 day resting phase (representing the time when the embankment is raised but deposition has not started). Then one month of deposition takes place before winter when no deposition takes place from this embankment due to the risk of freezing in the slurry pipelines. From 1 May three months of deposition is assumed, followed by 15 days of rest before the cycle starts all over again. The rate of rise for future raises is assumed to be three metres per year.

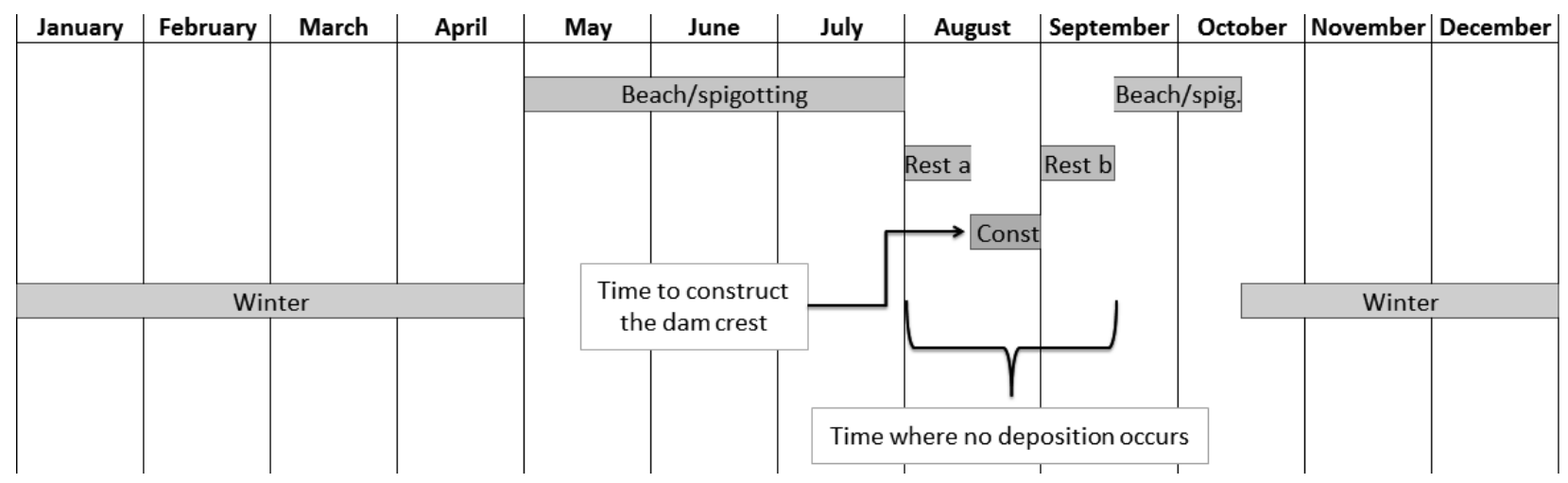

Figure 3 'Standard year' for planned events at the embankment

A schematic cross section of the embankment used in the model is presented in Figure 4. Here, future raises are presented as well.

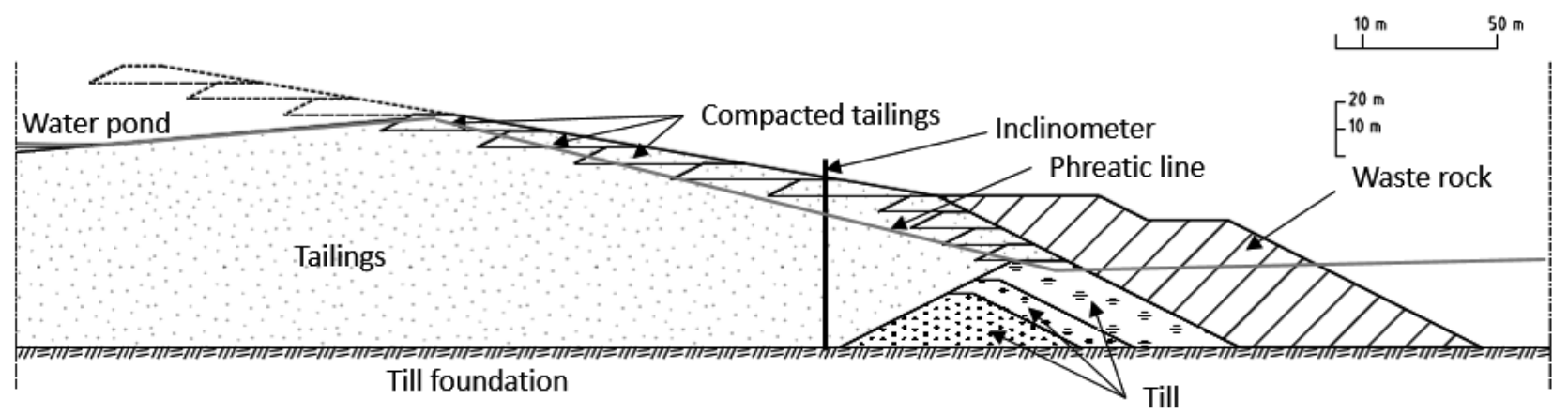

Figure 4 Cross section of the modelled embankment including subsequent raises after 2013 (dashed line)

The soil parameters evaluated from laboratory results were imported to PLAXIS. Thin regions of tailings with altering soil properties were used in the model in order to capture the stratigraphy seen from Cone Penetration Tests. For future events, soil properties were assumed to be the same as today's properties of embankment raises and deposited tailings. For other materials such as filters, till and waste rock there has not been the same degree of investigation during the 2013 'investigation campaign' regarding soil properties as the experience of general properties of these materials are larger. For these materials, the Mohr-Coulomb model is used where the soil properties are based on earlier geotechnical investigations (Sweco VBB 2008).

For all loading conditions in PLAXIS, the phreatic surface was assumed to be located at the tailings surface in the impoundment. From the crest of the embankment, the surface was assumed to be more or less linear to the homogenous downstream till embankment. This assumption corresponds to an average phreatic line according to field measurements (Jonasson 2013).

Simulations were performed where the loading conditions were modelled as staged constructions. The initial stage corresponds to the geometry that prevailed in 1992. Historical events were simulated for model confirmation purposes. For all stages, stresses and strains were analysed. In addition to that, the 
global FS was calculated for future events. For future loading conditions, a plan for increasing stability was created by adding waste rock on the downstream slope of the embankment in order to maintain the required $F S>1.5$. The waste rock wall on site will be raised with time. In other words, simulations of future loading conditions were performed by adding waste rock support fill until the required FS was reached. Results from simulations covering a ten year period are presented in Figure 5. By following the plan for waste rock support fill at the site, the calculated stability of the embankment was maintained as FS>1.5. The waste rock wall shown in Figure 4 will increase in height with time.

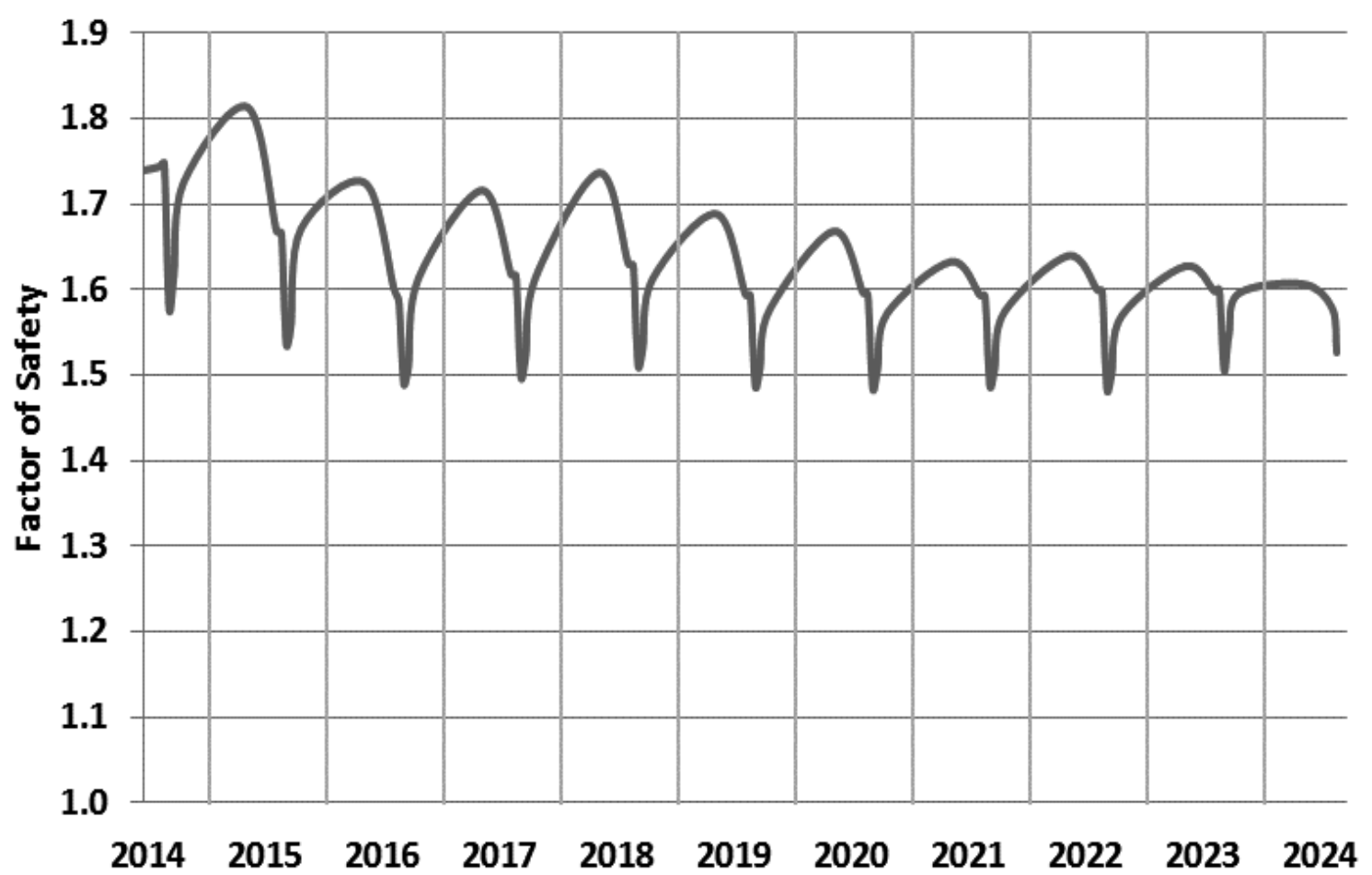

Figure 5 Calculated Factor of Safety (FS) for future events, here covering a ten year period

In Figure 5, the effects from the 'standard year' can be seen. Every time the embankment is raised, the FS is reduced to a value of 1.5. The reduction in safety is here due to generation of excess pore water pressure below the newly placed lift of the embankment. During the following events of the 'standard year' FS is again increased, which represents the time where consolidation takes place and the waste rock support fill is added on the downstream slope. When a new period of deposition and embankment raise takes place, the FS is again decreased. The waste rock support fill is here optimised so that the sought FS (>1.5) is maintained for the construction phases.

\subsection{Field data and model validation}

In dam safety operations, monitoring of embankments and their physical behaviour with time is a general approach. Properties such as pore water pressure, deformations and seepage are measured and continuously evaluated. The number and frequency of measurements varies between sites. Large and complex embankments are normally surveyed to a higher extent compared to small embankments.

There are different guidelines on embankment surveillance helping mine owners and engineers in setting up monitoring programs. What to be measured, type of equipment, and when to measure are examples of what are normally presented in such guidelines. When it comes to data interpretation and evaluation the procedures are not that standardised. An often used approach is to evaluate instrument readings in terms of trends, i.e. to identify changes over time. This is a good method in order to register sudden changes. These changes may indicate a risk and extra concern may be taken. This is, however, not as appropriate for tailings embankments as for water retention dams, mainly due to the non-static situation of tailings embankments since they are subsequently raised. If both the loading condition and water conditions are 
changed, which is the case when embankments and impoundment levels are raised, then changes in instrument readings are expected. However, whether the changes are in the serviceability stage or not cannot easily be interpreted.

In order to more easily interpret field data, there should be anticipated values for each instrument used. This was highlighted by Dunnicliff (1988) saying that without anticipated values, no abnormalities will possibly be recognised from field data. For complex structures such as tailings embankments, simulation is probably the best way to anticipate its behaviour. For example, each instrument in the embankment measuring pore water pressure should have values corresponding to the calculated stability. If the measured values are higher than expected according to the simulation, then the modelling input differs from reality and the stability might be of concern. In Figure 6 three alert stages are presented to be used for standpipes or piezometers. The pore water pressure corresponding to the minimum FS (here 1.5) represents the borderline to red alert stages. Higher pore water pressure would imply too low a FS. Lower pore water pressure would fall into green or yellow stages, both of which mean enough safety. Yellow alert stages imply excess pore water pressure that might prevail in fine grained tailings, but are expected and considered, i.e. in this case the plan for waste rock support fill compensates for that increase in pore pressure. Lower pressure, i.e. hydrostatic pressure, would fall into the green stage.

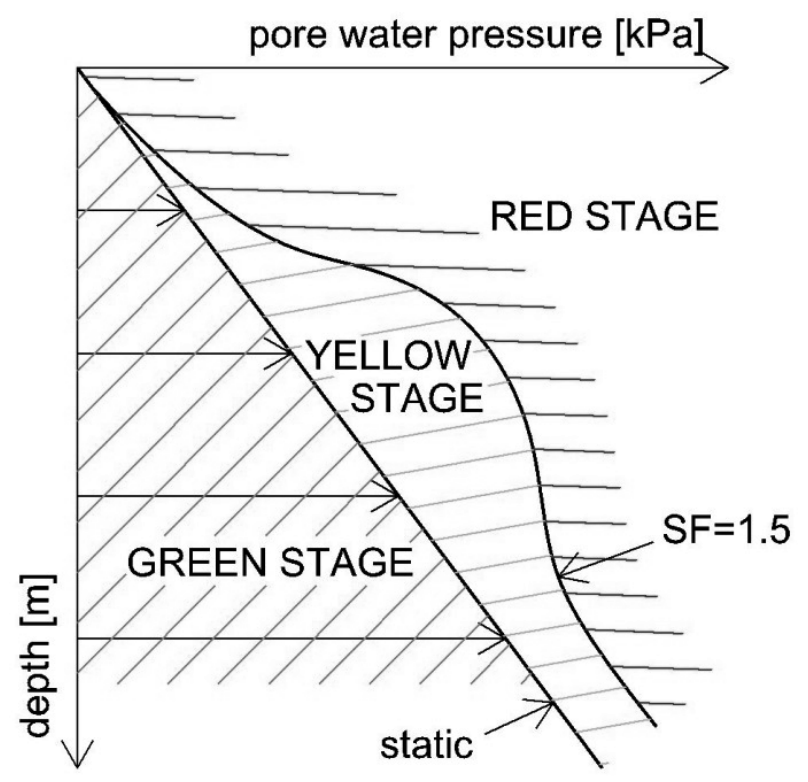

Figure 6 Schematic presentations of alert stages for pore water pressure instruments

Obviously, this methodology requires a good model that can simulate future behaviour. For this case study, the numerical model is validated by comparing the simulation of historical events (from 1992 up until today) with records of field data measurements. If the model is considered to simulate the behaviour of the embankment in a good manner, the same model can then be used for future predictions. Future predictions can also be used in order to relate future field measurements to the calculated stability.

While pore water pressure in an embankment can be considered as the cause behind possible stability problems, deformations can instead be regarded as the effect of possible stability problems (Dunnicliff 1988). Measurements of deformations in the embankment can therefore be regarded as the result of changes in stress. For this study, numerical results of deformations are compared with results evaluated from the inclinometer at the site. The inclinometer casing was installed in November 2007, and has since then been measured twice a year. The bottom of the casing is fixed $0.5 \mathrm{~m}$ into the bedrock beneath the embankment, where no deformations occur. The casing penetrates (from bottom up) $5.5 \mathrm{~m}$ of glacial till (natural ground), $27 \mathrm{~m}$ of tailings, $7 \mathrm{~m}$ of compacted till and $1 \mathrm{~m}$ of support rockfill on top. The location of the inclinometer casing is presented in Figure 4. 
Figure 7 presents the comparison in horizontal displacements between the field measurements and the results from the numerical model. The curves here represent data in November 2013 (latest reading available for the authors when the numerical modelling took place), which therefore indicates cumulative displacements over a six-year period. The continuous line represents field measurements, and the dashed line represents results from the numerical simulation.

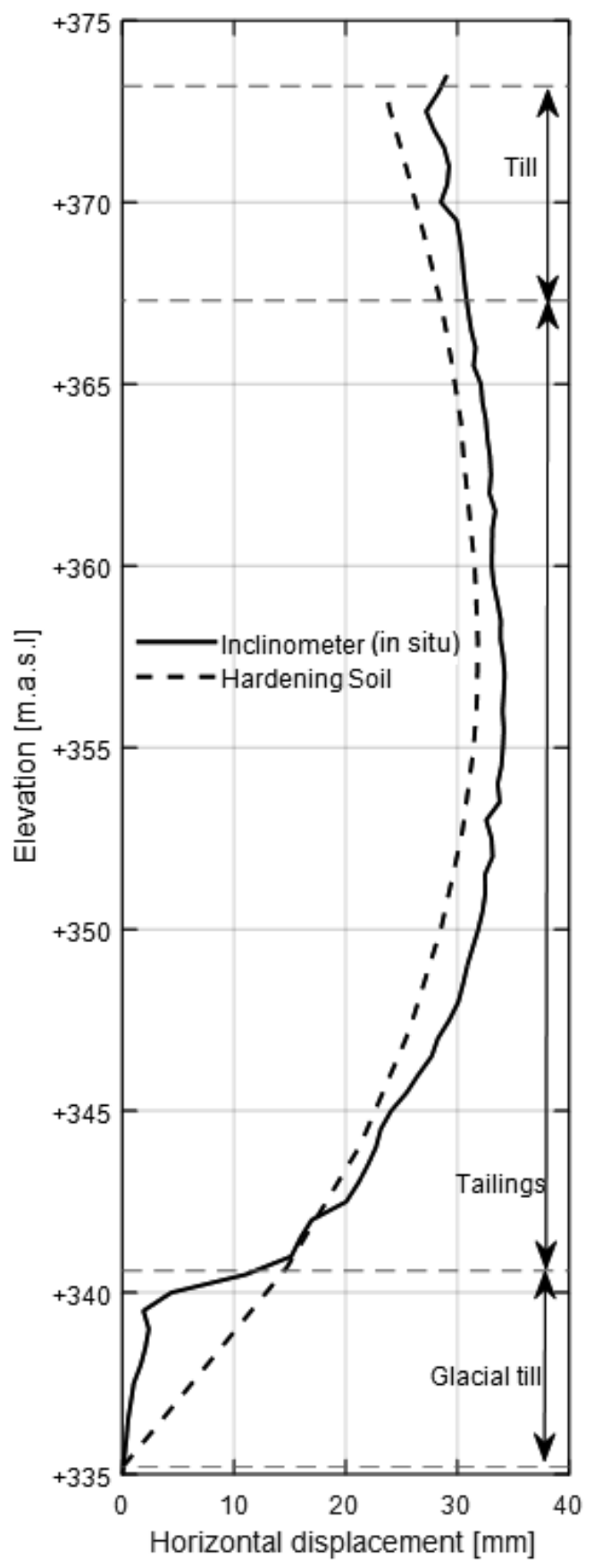

Figure 7 Measured horizontal, cumulative displacements by inclinometer (continuous line) and numerical results (dashed line). Time period: November 2007 to November 2013

The results from the numerical simulations indicate good agreement with field data. In general, the field data indicate slightly larger displacements in the tailings than was modelled. The slightly underestimated deformations (by modelling) are considered as a minor concern and the numerical results are according to the authors close enough to field observations in order to confirm the model and model parameters. Both curves have similar shapes, with the largest displacements in the middle of the tailings layer. Largest 
deviation between the two curves is in the underground till layer, which might be due to the fact that the simulation of this layer was performed with the linear elastic-perfectly plastic Mohr-Coulomb model.

\section{Discussion}

With the agreement between numerical results and field data in mind, the numerical model is considered to simulate the behaviour of the embankment in a good manner. With respect to different loading conditions over time, the model has captured the behaviour of the tailings and, correspondingly, the displacements at the location of the inclinometer at site. Since the deformations can be regarded as the result of stress changes, the agreement in displacements indicates that the model simulates the in situ stresses in a good manner. The stability analysis that was performed in addition to stresses and strains is therefore considered reliable as well.

In order to verify a certain FS for tailings embankments in the long term, i.e. landfill design post closure, a reliable model is proposed to be used in order to give as good a result as possible. Such a model should capture the different loading conditions and corresponding tailings behaviour. The methodology proposed in this paper is recommended for the build-up of such a model. By setting up a valid model that can be verified in operational aspects during operation of the TSF, the time of the simulation can then be extended, either to LOM in order to set alert levels or further to post-closure in order to estimate a safe long-term design. Of course detailed plans, or estimations, of activities at site should be included in such a model in order to capture the specific loading conditions at the specific site.

From the methodology presented, the importance of embankment surveillance is obvious. Field measurements should not only be used for evaluation of trends, or to observe sudden changes, as is often the custom. As presented here, the measurements can be used for validation of numerical models. If the numerical model is validated in terms of deformations, the corresponding stability is considered verified as well. Without such validations, the calculated safety is mainly a theoretical value that cannot be measured at site. Instead physical, measurable, properties should be used for these comparisons. For measurements taken after the modelling, there will correspondingly be anticipated values for the instruments which help in field data evaluation.

When it comes to advanced modelling of deformations, there is an obvious need for an increased effort in laboratory testing and applying the results into advanced constitutive models. Here, Hardening Soil was used for tailings, which simulate the stress-strain relations more accurately than linear-elastic perfectly plastic models (for example Mohr-Coulomb model). In addition to this, the loading conditions should be captured in the model. This can, for example be performed with staged construction models where historical events are taken into consideration. Even though more effort is needed for the model set up, the simulation gets more accurate and reliable.

A well-used method in stability analyses is the limit equilibrium method (LE) which analyses a failure mode without describing the behaviour of the structure, embankment, before failure. For such computations, there is only need for parameters describing strength (e.g. cohesion and friction angle) which leads to 'easier' modelling. On the other hand, such models can never be used for comparisons with field behaviour and the calculated stability is therefore not verifiable in that sense.

For the case study presented in this paper only operational aspects, such as construction of dam embankments and the waste rock wall, were taken into consideration. In terms of stability these aspects are considered as more critical than what is believed to happen at site after closure. The methodology presented in this paper is recommended for modelling and stability analyses for post-closure situations as well. With advanced constitutive modelling and simulations of historical events, comparisons between field observations and numerical results can be used for model validation. With such validation, the model is considered to accurately predict future dam behaviour. For analyses of future events, the calculated stability (FS) can therefore be coupled to anticipated values measured by the geotechnical instrumentation. The field measurements taken post closure, and the corresponding comparison to anticipated values or alert levels, can then be used for validating the slope stability. 
It should, however, be noted that in this study, no consideration has been taken of possible changes of the material properties with time. Changes in the used materials, as particle breakage, weathering of minerals, or possibly cementing and bonding effects, might result in different mechanical behaviour than those observed in the present laboratory testing. Another effect having a possible impact on the resulting stability is climate change. These effects are important and still not well understood, hence needing further research in order to provide a full understanding of the behaviour of tailings material and tailings embankments in a long-term perspective. For models where today's behaviour and stability is the main focus, these effects are probably of minor concern. But for long-term modelling such possible effects should be implemented in the constitutive models used.

\section{Conclusion}

Based on the results from this study, the following conclusions can be made:

- In order to verify the stability of an embankment, or landfill slope, during operation and/or postclosure, numerical modelling can be used efficiently.

- For verification of numerical models, comparison of measurable properties should be made, mainly between in situ measured data and corresponding simulated values obtained from the modelling. Without such verification, calculated stability and corresponding FS is mainly theoretical as it cannot be measured directly. Deformations, which can be regarded as the result of stress changes, were used here for comparison with numerical results.

- A method to set alert levels for dam safety based upon simulated and measured data is proposed.

- The proposed methodology, where numerical models are verified by field measurements, can be applied for dam safety operations in general. The actual FS is verified and field data interpretation is easier due to the possible comparison with simulated values.

\section{References}

Bhanbhro, R 2013, Oedometer tests - Aitik tailings dam (internal working document), Luleå University of Technology, Luleå, Sweden. Bhanbhro, R, Knutsson, R, Rodriqguez, JM, Edeskär, T \& Knutsson, S 2013, 'Basic Description of Tailings from Aitik Focusing on Mechanical Behavior', International Journal of Emerging Technology and Advanced Engineering, vol. 3, no. 12, pp. 65-69.

Brinkgreve, R, Enging, E \& Swolfs, W 2014, PLAXIS user's manual, Delft, The Netherlands.

Dunnicliff, J 1988, Geotechnical instrumentation for monitoring field performance, Wiley, New York, US.

GruvRIDAS 2012, Gruvindustrins riktlinjer för dammsäkerhet, Svensk Energi AB/SveMin, Stockholm, Sweden (in Swedish).

ICOLD (International Commission on Large Dams) 1996, 'Monitoring of tailings dams', ICOLD Bulletin 104, Paris.

ICOLD (International Commission on Large Dams) 2011, 'Improving tailings dam safety', ICOLD Bulletin 139, Paris.

Jonasson, F 2013, Geotekniska undersökningar, dam G-H och E-F, tolkning av geotekniska förhållanden samt utvärdering av portryck och rörelse I dammen, Uppdragsnummer 2168072800 (internal report), Sweco Infrastructure AB, Stockholm, Sweden (in Swedish).

Knutsson, R 2013, Triaxial tests - Aitik tailings dam (internal working document), Luleå University of Technology, Luleå, Sweden.

Marcato, G, Mantovani, M, Pasuto, A, Zabuski, L \& Borgatti, L 2012, 'Monitoring, numerical modelling and hazard mitigation of the Moscardo landslide (Eastern Italian Alps)', Engineering Geology, vol. 128, pp. 95-107.

Ostoprak, S \& Cinicioglu, SF 2005, 'Soil behaviour through field instrumentation', Canadian Geotechnical Journal, vol. 42, pp. 475-490.

Schanz, T, Vermeer, P \& Bonnier, P 1999. 'The hardening soil model: Formulation and verification', Proceedings of the International Symposium beyond 2000 in Computational Geotechnics, Amsterdam, The Netherlands, pp. 281-296.

Sweco VBB 2008, Förslag på materialparametrar för "Övriga material" vid beräkning i PLAXIS (internal report), SWECO VBB, Luleå, Sweden (in Swedish).

Vahdati, P, Levasseur, S, Mattsson, H \& Knutsson, S 2013, 'Inverse Mohr-Coulomb soil parameter identification of an earth and rockfill dam by genetic algorithm optimization', Electronic Journal of Geotechnical Engineering, vol. 18, no. X, pp. 5419-5440.

Yin, Y, Wang, H, Gao, Y \& Li, X 2010, 'Real-time monitoring and early warning of landslides at relocated Wushan Town, the Three Gorges reservoir, China', Landslides, vol. 7. pp. 339-349. 